\title{
Open access, at what costs?
}

\section{J. W. Foppe van Mil ${ }^{1}$}

Published online: 1 April 2019

(c) Springer Nature Switzerland AG 2019
What is truth? How can we try to ascertain that what you read in this journal is the truth? Are the articles published a true reflection of the research carried out and are the results presented clear, valid and reproducible?

Biomedical literature has a rich history of trying to ensure reliability and traceability: Peer review processes have been put in place, the National Library of Medicine (US) maintains a select index of journals (PubMed/Medline) which have met certain quality standards. Publishing the results of scientific research is a complex process. To make the report (paper, article or whatever you want to call it) unambiguous and clear, it must adhere to a certain format and undergo independent peer-review. Apart from the writing up, there should be a review and edit process to ascertain its quality as a study and as a paper.

\section{Access to research}

Research is funded by both private and public parties. As many interested parties decided in the 2000s, publicly funded research should be publicly available, free of charge, and access barriers should be removed.

But, what does free of charge really mean? The peer review, editing and publication process can never be free! There are costs involved in the reviewing, editing and publishing process, and these costs need to be covered somehow. Although printed versions of journals are gradually disappearing, the lay-out, indexing and platform hosting costs now must be considered. The estimates of the costs of processing a biomedical manuscript, from submission to online publication vary from $€ 3000$ to $€ 30,000$. Who pays?

It is clear that the user must pay, but which user? All STD publishers (belonging to the International Association of Scientific, Technical, and Medical Publishers) have

\footnotetext{
J. W. Foppe van Mil

jwfvmil@ijcp-editor.org

1 Zuidlaren, The Netherlands
}

traditionally sold subscriptions to their journal portfolio, which they have organized, curated etc., and provided paid access to individual manuscripts. In exchange for the publishing rights of a manuscript (yes, your research), they have invested their expertise to make sure that the reports of you your study are presented in a scientifically correct way, accessible, and distributed as widely as possible. However, we can also ask the researchers to pay. The publishing model that most politicians and funders now seem to embrace, is called 'Open Access'. Access to the manuscript is free, but the researchers (yes, you) foot the bill; in which case, it could be argued that the cost of open access publication should be included in the research budget.

A consortium of European funders led by the ERC is now also pursuing Open Access for data and publications derived from all European funded projects. These proposals would require anyone in receipt of a grant to make their work Open Access at the point of publication [1]. Under Plan S of Science Europe (a funders' lobbying organisation), it is expected that from 1 January 2020, all scholarly publications resulting from public research funding must be published in Open Access journals or on Open Access platforms [2].

In addition to Open Access, the European Research Council (ERC) also promotes the deposition of reports and papers in open access repositories, such as Zenodo, Figshare, Dryad or other subject specific repositories.

\section{Danger!}

Open Access, in general, seems an excellent concept, if the costs of publishing are included in funding budgets and grants etc. But looking from a publisher's and wider scientific community's perspective, who is then providing quality assurance for the validity of the study and research, and the quality of the manuscript? If an individual researcher pays then, maybe, the quality of a study or manuscript is no longer necessarily the concern of the publisher. So-called 'predatory' journals discovered this hole in the market, and accept whatever paper of whatever quality as long as it is 
being paid for. Alternatively, articles are now being deposited in open access repositories, without any peer review or formatting requirements.

An extra consideration in this web of publishing is the fact that there are many researchers from less developed areas who cannot afford to pay an open access fee, and therefore find it very difficult to publish under the Open Access model. Where should they publish their research if Open Access becomes the dominant and mandated model across the world? Would we again be creating a new inequality?

Even if your study is so excellent that it would be accepted for publication in Nature, would you be able to find the fee of 30.000-40.000 Dollars to get it published? This sum of money usually represents the total budget for any clinical pharmacy/social pharmacy study. Only very commercial parties or substantial consortia-type research groups can afford these amounts, making inequalities even wider.

Lastly, from the viewpoint of traceability, the biomedical research community relies heavily on PubMed/Medline to keep up to date with the latest publications. Posting data in different institutional repositories creates a findability problem, since they are generally unknown and do not have a single search engine.

\section{Conclusion}

The International Journal of Clinical Pharmacy is focussed on safeguarding the quality of the papers published and is quite satisfied with the hybrid model currently available to its authors and readers. Under this model we can assure quality of all presented studies and papers we publish and all potential authors can submit their work and get it published.

Open access is a good concept for those who can afford it. Whether the publishing model is based on article processing charges (like Open Access) or subscription-based, the action of publishing has costs to endure, and the debate on which is best will continue to take place for some time to come. But for the scientific community, in general, it is not a good thing that articles, reports and data can be deposited in open access repositories, without first an independent scrutiny of quality and format, and without a universal master index being in place.

The current direction being taken by the cOAlition $\mathrm{S}$, probably serves the interests of many organisations, but not necessarily that of the individual academic researcher or the general public. For those with limited financial resources, the traditional biomedical science publishing model is still very important and affordable, and it represents an unparalleled traceability and findability for all.

Funding None.

Conflicts of Interest None.

\section{References}

1. European Research Council. Open Access at https://erc.europa.eu/ funding-and-grants/managing-project/open-access. Last Accessed 20 Feb 2019.

2. Science Europe AISBL. 'Plan S' making open access a reality by 2020. https://www.scienceeurope.org/making-open-access-a-reali ty-by-2020/. Last Accessed 20 Feb 2019.

Publisher's Note Springer Nature remains neutral with regard to jurisdictional claims in published maps and institutional affiliations. 